Argonne

Report ANL-18/13

\title{
Urban Landscape and Climate Change
}

Workshop Summary

Environmental Science Division and

Mathematics and Computational Science Division 


\begin{abstract}
About Argonne National Laboratory
Argonne is a U.S. Department of Energy laboratory managed by UChicago Argonne, LLC under contract DE-AC02-06CH11357. The Laboratory's main facility is outside Chicago, at 9700 South Cass Avenue, Argonne, Illinois 60439. For information about Argonne and its pioneering science and technology programs, see www.anl.gov.
\end{abstract}

\title{
DOCUMENT AVAILABILITY
}

Online Access: U.S. Department of Energy (DOE) reports produced after 1991 and a growing number of pre-1991 documents are available free at OSTI.GOV (http://www.osti.gov/), a service of the US Dept. of Energy's Office of Scientific and Technical Information.

Reports not in digital format may be purchased by the public from the National Technical Information Service (NTIS):

U.S. Department of Commerce

National Technical Information Service

5301 Shawnee Rd

Alexandria, VA 22312

www.ntis.gov

Phone: (800) 553-NTIS (6847) or (703) 605-6000

Fax: (703) 605-6900

Email:orders@ntis.gov

Reports not in digital format are available to DOE and DOE contractors from the Office of Scientific and Technical Information (OSTI):

U.S. Department of Energy

Office of Scientific and Technical Information

P.O. Box 62

Oak Ridge, TN 37831-0062

www.osti.gov

Phone: (865) 576-8401

Fax: (865) 576-5728

Email: reports@osti.gov

\section{Disclaimer}

This report was prepared as an account of work sponsored by an agency of the United States Government. Neither the United States Government nor any agency thereof, nor UChicago Argonne, LLC, nor any of their employees or officers, makes any warranty, express or implied, or assumes any legal liability or responsibility for the accuracy, completeness, or usefulness of any information, apparatus, product, or process disclosed, or represents that its use would not infringe privately owned rights. Reference herein to any specific commercial product, process, or service by trade name, trademark, manufacturer, or otherwise, does not necessarily constitute or imply its endorsement, recommendation, or favoring by the United States Government or any agency thereof. The views and opinions of document authors expressed herein do not necessarily state or reflect those of the United States Government or any agency thereof, Argonne National Laboratory, or UChicago Argonne, LLC. 
ANL-18/13

\section{Urban Landscape and Climate Change}

Workshop Summary

prepared by

Beth Drewniak ${ }^{1}$, Rao Kotamarthi ${ }^{1}$, Rob Jacob ${ }^{2}$, Fei Chen ${ }^{3}$, and Charlie Catlett ${ }^{2}$, with input from Jason Ching ${ }^{4}$ and Wei $\mathrm{Wu}^{5}$

${ }^{1}$ Environmental Science Division

Argonne National Laboratory

${ }^{2}$ Mathmatics and Computational Science Division

Argonne National Laboratory

${ }^{3}$ National Center for Atmospheric Research

${ }^{4}$ University of North Carolina

${ }^{5}$ Brookhaven National Laboratory, ${ }^{*}$ currently at NOAA/NOS/CSDL

August 2013 


\section{Contents}

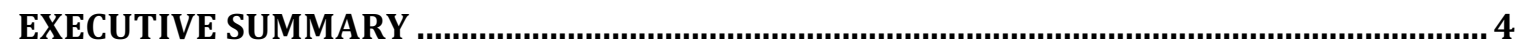

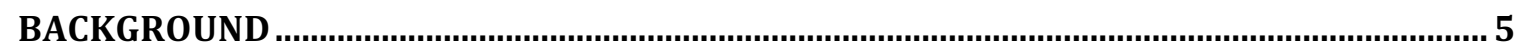

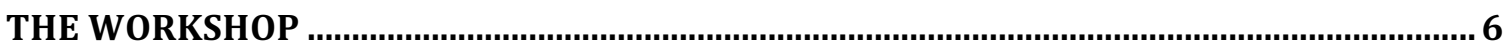

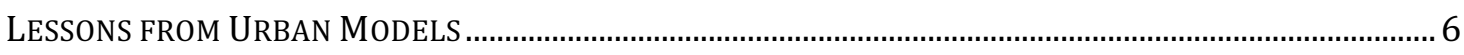

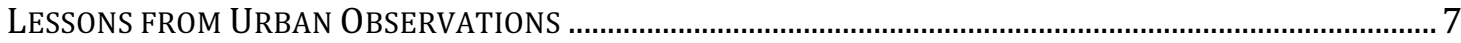

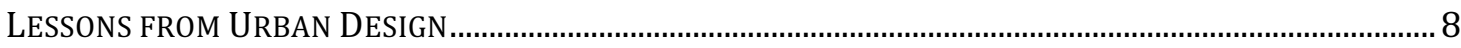

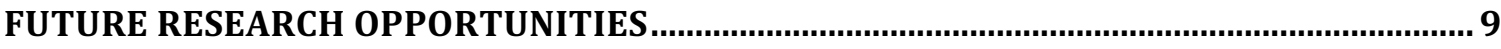

AGENDA: URBAN LANDSCAPE AND CLIMATE CHANGE ..............................................11

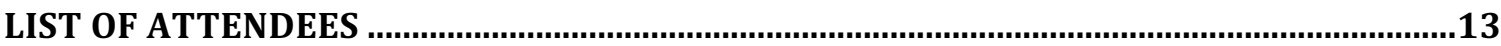




\section{Executive Summary}

A workshop on how earth system models incorporate the influences of urban environments on climate, with an emphasis on how large observation studies can be used to aid the modeling community, was held on August 27-28, 2013 at Argonne National Laboratory. The goal of the workshop was to identify urban processes important in influencing the predictive capability of regional climate models and global earth system models, the impacts of climate change that are important for future urban centers, data available or needed to develop a representative model of urban ecosystems, and how cities can use that information to improve the lives of their residents.

The workshop participants identified the priorities listed below for the next five years of model development and observational framework.

\section{1) Cataloging data archives to develop model testbeds}

One of the most important needs identified at the workshop is a model testbed that can be used for data assimilation, parameter evaluation, and development of new parameterizations. A critical need included a central repository for urban observational data sets that will work in tandem with the model testbed, and would include a significant number of urban studies conducted previously by organizations across the world. Computer software to host such data is available (e.g., Earth System Grid). Data types should include atmospheric, air quality, hydrology, urban properties, and socioeconomic features. As new campaigns are conducted, the data collected can be added to the repository. One cost effective approach might be to identify available candidate cities that already have comprehensive urban databases (e.g., Paris, London, Houston, New York City, Baltimore, Phoenix) that with suitable investments could be selectively and expediently augmented to serve as modeling testbeds for both evaluating parameterizations and developing new parameterizations. Improving the urban microclimate by process-scale descriptive models, such as the UCP (Urban Canopy Parameterizations) using well-designed companion field measurement campaigns as discussed earlier, are needed.

\section{2) Designing field campaigns}

The design should integrate in situ measurements and remote sensing tools, while leveraging alternative data sources (e.g., geowiki, citizen science) that can provide information on transportation, energy use, geometry, city form and function, etc. Collaboration with stakeholders and community members is a must, not only to sustain ongoing projects, but also to understand the future direction of the city and ensure collection of data that would not be available otherwise. Finally, observations should extend beyond the city boundaries to include surrounding rural or forested systems or bordering bodies of water (e.g., ocean or lake) such that we can begin to strengthen our understanding of the coupling across the land surface gradient. The goal should be the establishment of a long-term urban observatory to further our understanding of poorly understood urban processes and provide baseline data for models.

\section{3) Building networks}

Data collection should be established through networks. The network should act to coordinate and organize efforts such that long-term baseline data that includes a wide 
variety of data sources is collected over both rural and urban sites. Networks can be designed to communicate data over local scales or across a wide range of long-term field campaigns. However, networks can also connect different interest groups whose research targets various aspects of urban environments. Synergistic activities across the urban domain should be integrated to maximize data availability and flow.

\section{4) Model development}

Model development needs to take into account the unique properties of cities and the heterogeneity within them. One approach could be to generate properties of a variety of idealized cities types to represent different regions, such as those targeted for the World Urban Database And Portal Tool (WUDAPT). Climate models also need to take into account changes in cities over time. This includes possibly integrating an urban growth model or accounting for changes in land use and land cover. A helpful approach will be to interact with city planners who have already mapped out future designs and function of the city over short and long time scales. Future city models should include information on adaptation and mitigation. Developing scenarios to consider impacts from changes in human behavior and city design can be explored, but should involve community engagement. Of course, despite the availability of big data, and the computational power to collect and store information, models still cannot ingest all the types and forms of data. Therefore, effort to use data assimilation will be a critical component of model development.

Research on forests has improved our biosphere models and overall GHG analysis and climate modeling. The work started with studying trees, forests, and types of landscapes to develop research community and model formulations. A similar approach is needed for urban processes. Starting with buildings, cities, and different representations that can be improved upon, integration within an urban modeling system could build off of and complement current models.

\section{Background}

Urban landscapes can have significant impacts on the environment through modifications to albedo, surface roughness, aerosol concentration, runoff, etc. As a result, urban centers influence weather and climate at local and regional scales, with a direct impact footprint that extends between two to three times the actual urban spatial extent. Although total urbanized surface over the globe is relatively small compared to vegetated surfaces, considering urban centers house a majority of the world's population, the interaction between local climate and urban landscapes has the ability to impact the health and wellbeing of a large number of communities. Urban areas have particular landscape characteristics including unique land cover features, built infrastructure for commercial, housing and transportation, and high density energy and water consumption. These characteristics determine urban-land-surface properties and are critical for generating accurate weather forecasts and modeling urban-climates. These urban properties can modify the atmospheric boundary layer, distribution of energy within the atmospheric column, hydrologic processes, surface temperature, precipitation and air quality. Representing urban areas in climate models not only improves simulations over urban landscapes (which now cover more than $5 \%$ of the land surface and include $50 \%$ of the human population), but is necessary to improve climate projections over regions 
surrounding the urban area. Including urban-land-surface properties that modify boundary and initial conditions in weather-forecast and climate models will improve modeled outputs compared to models with no or poor representation of urban landscapes. This requires integrating urban features in climate models to make actionable climate change impact predictions over both urban and nonurban landscapes.

The workshop joined a diverse group of scientists interested in urban and climate interactions, both simulated and observed, to discuss the challenges and techniques in representing urban landscapes in climate models. Breakout sessions fostered discussion on how measurements and modeling can work together better to improve our understanding of the interaction between climate change and urban landscapes. The goal of the workshop was to identify gaps in current understanding of urban processes that will be important at climate model scales and determine future areas of focus for data collection and observatory design.

\section{The Workshop}

The 1.5-day workshop was broken into four sessions and two split breakout groups each day. Modelers, observers, and risk assessors were brought together to discuss topics across boundaries. Workshop breakdown is as follows:

- A joint session focused on the current state of urban studies, both for models and data.

- A second joint session was on observations of the urban environment.

- A third joint session included presentations on modeling the urban environment.

- Two breakout sessions were tasked with (1) outlining a comparison of observations and models, and (2) modeling the urban-climate connection, after which the group reconvened to provide breakout reports.

- The final joint session considered the interaction between urban design and urban climate with some presentations considering risk and adaptation of cities to climate change.

- Two final breakout sessions discussed (1) designing urban observatories, and (2) applications of urban-climate models, following a final joint session to report breakout discussions.

\section{Lessons from Urban Models}

The plenary presentation by Keith Oleson introduced the current state of urban representation in the Community Land Model. Dr. Oleson noted that the shortcomings of most climate models over urban areas are the use of idealized urban properties that do not vary over large regions, the current coarse resolution of urban areas in models, the lack of anthropogenic heat flux in models, and the missing future form and function. The discussion following focused on the possibility of developing types of idealized cities that could represent various regions across the world.

Fei Chen noted the model sensitivity to thermodynamic processes driving changes to the timing, location, duration, and magnitude of precipitation events. Dr. Chen showed that models underestimate latent heat flux by not considering irrigation, urban oasis effects, pavement runoff/evaporation, and anthropogenic moisture sources. Using atmospheric and urban data assimilation techniques could improve the models. 
Jorge González-Cruz discussed the unique response of coastal cities to climate change through strong coupling between the coast and ocean. Particularly, the urban heat island (UHI) is suppressed by increases in the sea breeze from faster-warming inland urbanization. Prof. González-Cruz stressed the importance of long-term climate records and urban properties at high resolution for future forecasting.

Robert Bornstein demonstrated the importance of having a good reference comparison. For example, UHI at the surface could be small, but large aloft; strength of the UHI will vary depending on dry or moist conditions; and background flow will contribute to the UHI or precipitation event. Ultimately, the urban climate model will need to bridge a scale gap several orders of magnitude, coupling the city to regional and global scales. This achievement could involve linking different types of urban models (e.g., LES, CFD), through downscaling and upscaling methods, or implementing parameters at sub-grid scale.

Dev Niyogi showed heterogeneity across the urban area (e.g., green roofs, vertical gardens and agriculture, surface roughness) has a strong impact on the timing, location, intensity, and magnitude of precipitation events. This effect is well beyond the city limits extending to 2-3 times the areal extent. Storms moving across a rural to urban gradient tend to split and intensify after regenerating downwind of the city with maximum rainfall occurring up and downwind of the urban center. However, storms that are generated in calm conditions tend to have maximum precipitation over the city with minimum rainfall downwind of the storm. Finally, aerosol effects could be responsible for an increasing trend in heavy rainfall events in cities with rapidly growing populations.

\section{Lessons from Urban Observations}

The plenary talk given by Jason Ching highlighted the need for modeling inputs commensurate to the grid resolution and fit-for-purpose data with specific types of applications through the development of scale-dependent parameterizations to upscale urban-land-surface properties. Two important inputs need to be addressed: (1) descriptors of land surface properties, and (2) urban physiology, i.e., energy requirements and waste products. Regarding descriptors, the increasingly finer grid mesoscale models will require urban model morphological descriptions in terms of grid size appropriate canopy parameters, thermal and reflective properties. Climate models will require subgrid scale treatments of such parameterizations and/or facets of morphological features and for neighborhood and building scale applications, detailed information on form and substance of individual morphological features of buildings and vegetation. Further, for overall considerations of risk and sustainability assessments, the information base will need to adjust to changes with increased urbanization and/or renewals, thus requiring dynamic city growth models. Finally, given that climate change impacts are worldwide, databases for model applications are needed on a commensurate scale. Currently, the status of meeting the desired and required input data is unmet, and highly variable in terms of coverage and responsiveness to the increasing science bases of urban models. Physiologically, inputs needed are energy from HVAC and traffic usage, both on current and future demand bases, and both spatial and temporal patterns resolved throughout urban areas. 
Elie Bou-Zeid presented evidence showing the increase in temperature over urban areas resulting from the urban heat island (UHI) effect, largely due to the modification to land use and concentrated energy use within the urban canopy. Prof. Bou-Zeid showed the UHI amplifies heat waves and increases its duration, which is largely missing in models due to lack of hydrology. The drastic modification of land surface due to surface paving and built infrastructure can create an environment of low evaporation within the urban area that modifies the local energy balance. Current models do not include processes such as irrigation, pavement runoff, evaporation from impervious surfaces, and anthropogenic water sources.

David Kristovich demonstrated the unique interaction between coastal cities with climate by increasing or decreasing the lake/sea breeze. Surface roughness, topography, heat circulation, and neighboring cities will influence the effects on the lake/sea breeze. The strong coupling between ocean and land near coastal cities should also be considered in climate models. The offshore to urban gradient drives feedbacks to rainfall and the urban heat island circulation. Modeling the diurnal evolution of the heat island would strengthen our understanding of these systems, rather than when treated separately.

James Voogt argued that urban models do not have a lot of information on soil moisture or how heterogeneity influences snowpack, which is a strong driver for hydrology processes. Prof. Voogt also discussed the importance of sensor placement, as observations at the surface have different sources than observations above the canopy. In addition, canopy sensors should be placed to measure parameters that will be representative of the urban center, since flow patterns will determine what source effects will be measured.

Petra Klein gave a presentation that showed that the shape of the urban influence depends on the regional or synoptic flow patterns, resulting in a bubble or plume over the urban center with a characteristic elongation along the mean flow direction. Soil moisture interactions from irrigation and impervious surfaces surrounding the urban core play a strong role in the shape and extent of this UHI dome. The changes in local energy distribution, addition of anthropogenic heat sources and large modifications surface roughness in an urban environment significantly alters the boundary layer dynamics and determines the magnitude and scale of UHI. Dr. Klein mentioned that the differences in mixing and turbulence in the urban canopy compared to rural regions has important consequences for air quality, temperature and precipitation observations across the urban-rural boundaries. Therefore it is important to also capture connections across the rural to urban centers, which requires proper modeling of the rural component as well.

\section{Lessons from Urban Design}

Ashish Sharma and Laura Leo showed a means of using cheap infrastructure to generate high spatial UHI maps in real time with potential for long-term monitoring to understand the impact of heterogeneity on UHI.

Alex Mahalov presented the positive feedbacks from urban waste heat when air conditioning is included in models. 
Patricia Romero-Lankao stressed that varying ability of cities to react to climate change will result in unique responses for each city. This highlights the importance of scaling multidisciplinary data, both up and down.

Charlie Catlett delivered a talk on partnering with cities to deploy sensor networks and making data open and available to share.

Paul Kirshen talked about the adaptability of human nature in urban systems, which will allow a mix of actions to be taken over time and space, and should be taken into account in climate models. A range of future conditions will drive future urban design. City planners have these plans in place, which could be useful for developing urban growth models.

\section{Future Research Opportunities}

The workshop identified the need for intensive field measurement in order to answer questions about hydrology, thermodynamics and dynamics in urban systems. Data collected should take into account the significant impacts of urban centers on regional climate that are amenable for a field campaign, and the time and spatial scales of data needed to address science questions. Current remote sensing tools and techniques will play a key role in data collection. Field campaigns should be designed to address scientific questions such as (1) how does skin temperature, compared to air temperature, contribute to energy fluxes; (2) how does anthropogenic heat flux change over time; (3) what is the vertical profile of an urban canyon; or (4) how does heterogeneity (facet scale fluxes) contribute to the urban heat island circulation?

One approach could be to establish a long-term urban observatory, which focuses on urban weather and climate, but brings together physical, social, and ecological scientists. The observatory should be an extended network encompassing different types of urban cities in different regions (e.g., desert, coastal, plains), designed to capture long-term climate and surface properties. The infrastructure linking the network could be virtual or physical.

There are a number of things that must be done in order to capture these impacts in climate models. First, we need good-quality measurements on urban-land-surface processes that influence urban energy/moisture fluxes, boundary layer dynamics, temperature, etc. Second, we need to identify urban properties that are important drivers of the above processes and develop parameterizations to accurately represent the urbanland-surface in weather forecast and climate models. Third, we need good-quality measurements to validate model improvement after the additions of urban-land-surface properties into models. Finally, perhaps the most important consideration for including urban landscapes in climate models is the issue of scale. With climate models moving to high resolution, the urban footprint is more obvious. However, modeling the urban center correctly still requires bridging across multiple scales, with processes ranging from LES to mesoscale, and identifying micro-scale processes that will still be important at the macro-scale and downscaling/upscaling procedures that can be applied in nested grids of regional climate models. This paper has discussed the needs of the climate community as well as an approach to strengthen our understanding of urban processes through data 
collection. Moving forward will increase the power of future urban observations and the predictability of climate models. 


\section{Agenda: Urban Landscape and Climate Change}

Day 1 August 28, 2013

8:30-8:50 Welcome and Opening Remarks (Rick Stevens)

8:50-9:00 Workshop Motivation and Logistics (Beth Drewniak, ANL)

Session 1: State of Urban Studies (Chair: B. Drewniak, ANL)

9:00-9:30 Representing Urban Areas in Global Climate Models: Progress and Data Needs (K. Oleson, NCAR)

9:30-10:00 Urban canopy modeling and data needs for urbanization and climate effect assessments (J. Ching, University of North Carolina)

Session 2: Observations of the Urban Environment (Chair: R. Kotamarthi, ANL)

10:30-10:50 Heat Waves and the City: Challenges in Understanding and Mitigating Urban Extreme Heat (Elie Bou-Zeid)

10:50-11:10 Urban Observations: Insights from the Environmental Prediction in Canadian Cities (EPiCC) Project (J. Voogt)

11:10-11:30 Spatial and Temporal Characteristics of the Oklahoma City Urban Heat Island (P. Klein, University of Oklahoma)

11:30-11:50 Energy Exchange between Urban Surfaces and the Surrounding Environment (J. Frederick, University of Chicago)

11:50-12:10 Observed influences of Chicago on lake-breeze inland movement: Climatological approach (D. Kristovich, University of Illinois)

Session 3: Modeling the Urban Environment (Chair: F. Chen, National Center for Atmospheric Research)

1:10-1:30 Integrated WRF-Urban Modeling System: recent model development and validation (F. Chen, NCAR)

1:30-1:50 Urban mesomet models: current status, problems, and solutions (R. Bornstein, San Jose State University)

1:50:2:10 Urban Climate (Dev Niyogi, Purdue University)

14:10-3:30 On the understanding of changing coastal urban landscapes and regional climate signals (J. Gonzalez Cruz, City College of New York)

3:30-3:50 Urban modeling results of an air quality urban climate modeling study centered over DallasFort Worth (J. Bowden, University of North Carolina)

Session 4: Breakouts: Improving the design and parameterization of urban models; discrepancy between empirical studies and models

Group 1: Comparison of observations and models

- What is the best current agreement between models and observations in urban meteorology/climate?

- What information is currently available to inform models?

- What are the methods and challenges to overcome to represent process $\mathrm{X}$ in models?

- What do we most want to measure but can't and what are the obstacles?

- What do we most want to model but can't and what are the obstacles?

Group 2: $\quad$ Modeling the urban-climate connection

- What are the gaps in our knowledge of urban influences on regional climate change (i.e. processes that are poorly understood or not parameterized well)?

- What processes in urban landscapes drive effects on climate? Which ones are missing from current models? What is the relative importance of each process with respect to climate impact?

- At what scales do different processes become important?

- What type of model is needed to represent urban processes effects on climate? Does this vary with application?

4:30-5:00 Reports from breakout groups and adjourn

Day 2 August 29, 2013 
Session 4: Interaction between Urban Design and Urban Climate (Chair: Charlie Catlett, ANL / UChicago)

8:30-8:50 Impact of climate change on urban heat island (A. Sharma and L. S. Leo)

8:50-9:10 Modeling Energy Impacts and Climate Adaptation: Seeking Sustainable Solutions for Rapidly Expanding Urban Areas (A. Mahalov)

9:10-9:30 Urban Center for Computation and Data (C. Catlett, ANL/UChicago)

9:30-9:50 Urban Risk and Response Capacities in Neighborhoods Urban Latin America and Asia (P. Romero-Lankao, NCAR)

9:50-10:10 Progressive Adaptation of Urban Infrastructure to Climate Change (P. Kirshen, University of New Hampshire)

Session 5: Breakouts: Data needs for urban processes for model development

Group 1: Designing Urban Observatories

- What is the current state-of-the-art for urban observatories?

- What types of data are currently being collected? At what scales?

- How has large amounts of urban observations advanced our understanding of urban landscapes?

- Is data collected in such a way that the uniqueness of each urban ecosystem can be determined?

- What is the data rate from urban observatories and what strain to they put on current analysis methods and hardware.

- What is the best method to process big data from urban observatories?

- Do we need new algorithms for big urban data?

- How feasible is it to expand the types of data collected in urban observatories?

- What is the importance of quality vs. quantity?

- Can urban meteorological data be combined with other urban data for societal benefit?

Group 2 Applications of urban-climate models

- Should models use data assimilation, process based functions, or a combination of both to simulate the environment?

- How can models be adaptive to include the rapidly changing urban landscape and the uniqueness of each urban environment?

- How can we build urban models suitable for future predictions (not over-fitted to current conditions)?

- What types of models can be used to inform local governments of impacts of climate change on urban developments?

- How can we use urban-climate models to inform urban design decisions for climate change adaptation and mitigation?

Session 5: Report from Breakout Groups and General Discussion

11:45-1:00 Reports and Discussion

13:00 Adjourn 


\section{List of Attendees}

\begin{tabular}{|l|l|}
\hline Name & Affiliation \\
\hline Robert Bornstein & San Jose State University \\
\hline Elie Bou-Zeid & Princeton \\
\hline Jared Bowden & University of North Carolina \\
\hline Edwin Campos & ANL \\
\hline Charlie Catlett & ANL/UChicago \\
\hline Fei Chen & NCAR \\
\hline Jason Ching & University of North Carolina \\
\hline Beth Drewniak & ANL \\
\hline Thomas Dunning & NCSA \\
\hline John Frederick & University of Chicago \\
\hline Jorge Gonzalez Cruz & City College of New York \\
\hline Robin Graham & ANL \\
\hline Leah Guzowski & ANL \\
\hline Marc Imhoff & PNNL \\
\hline Robert Jacob & ANL \\
\hline Paul Kirshen & University of New Hampshire \\
\hline Petra Klein & University of Oklahoma \\
\hline Rao Kotamarthi & ANL \\
\hline David Kristovich & University of Illinois \\
\hline Laura Leo & University of Notre Dame \\
\hline Alex Mahalov & Arizona State University \\
\hline Robert McGraw & BNL \\
\hline Michael McGuigan & BNL \\
\hline Dev Niyogi & Purdue \\
\hline Keith Oleson & NCAR \\
\hline Rob Pennington & NCSA \\
\hline Patricia Romero-Lankao & NCAR \\
\hline Paul Schmid & Purdue \\
\hline Ashish Sharma & University of Notre Dame \\
\hline James Voogt & University of Western Ontario \\
\hline Jiali Wang & ANL \\
\hline Wei Wu & BNL; Currently: NOAA/NOS/CSDL \\
\hline Laura Zamboni & ANL \\
\hline & \\
\hline
\end{tabular}




\section{Argonne}

\section{Environmental Science Division}

Argonne National Laboratory

9700 South Cass Avenue, Bldg. 240

Argonne, IL 60439

www.anl.gov 